\title{
Off campus students' experiences collaborating online, using wikis
}

\author{
Debbi Weaver, Shane Viper, Jennifer Latter and P. Craig McIntosh \\ Swinburne University of Technology
}

\begin{abstract}
An online group work project for off campus students, using wikis as the collaboration platform, has been conducted successfully for several years. Students were given the opportunity and technical means to collaborate, and staff could assess individual students' participation. However, the actual level of collaboration was less than hoped for, especially in early iterations of the unit. While the teaching staff are confident that, for the overall student cohort, collaborating online using a wiki is meeting the needs of most students, this is varied across the diverse cohort. To gain further insight into the internal machinations of student groups, selected students were invited to submit their experiences of their wiki project. This paper reports the personal stories of two off campus students, and compares the experiences described by our students with the teaching staff members' perceptions. The two students featured were selected not just for their articulate writing, but because their group experiences were quite different. Considering these students' experiences has allowed the teaching staff to reflect on how to better support our students during their group project.
\end{abstract}

\section{Introduction}

Recent years have seen exponential growth in the delivery of higher education online, both as part of a blended approach, where on campus students access some of their materials and activities online, and fully online, catering to a wider cohort of students both on campus and off campus. At the same time, the higher education community has recognised that a more learner-centred approach can be encouraged by increasing the opportunities for student-student interaction and collaboration (Heejung et al., 2008).

Most institutions providing online courses now provide opportunities in at least some subjects for students to participate in collaborative learning projects so that students experience opportunities for sharing and constructing knowledge (Dewiyanti et al., 2005). Uptake by students varies greatly and appears highly dependent on the context (Carr et al., 2007), and the benefits for students appear similarly dependent on the processes employed:

When effective group management processes are employed, clear assessment guidelines developed and communicated and valid and fair grading processes employed, the likelihood of positive learning outcomes and student satisfaction with group activities is significantly increased. Alternatively, if students cannot see the objective of group work, are unsure of what is expected of them, or believe the assessment methods are invalid or simply unfair, the educational benefits are reduced and tensions can emerge (James et al., 2002, p1). 
The advent of social networking technologies has enabled greater opportunities for online collaboration. Wikis in particular are increasingly being used for group projects, both for students working fully online and for those studying in a blended format. Wikis allow students to work together on the same version of their assignment, and include a range of communication tools for students to discuss their work. The outstanding strength of the wiki format is that it provides the opportunity for collaboration and is 'designed to facilitate exchange of information within and between teams' (Goodnoe, 2005, cited in Minocha \& Thomas, 2007). Wikis have already been used successfully in higher education: to enable hundreds of students to participate in a collaborative icebreaker exercise at Deakin University (Augar et al., 2004); and for students to work together on a problem-solving exercise in Biomedical Science at Monash University (Brack et al., 2007), amongst others for example, Raman, Ryan and Olfman (2005).

The use of wikis opens up a new realm of collaborative sharing and creation of knowledge through learning conversations, where the process is as important as product, the audience is involved in the process, and notions of control over the product may be relinquished by the individual (Carr et al, 2008, p.268).

To date, little has been published from the students' perspective of online collaboration. Recent work by Zorko (2009) focused on students' use of the wiki software and their communications with each other, and identified useful recommendations for improving wiki projects for students, but did not venture into the dynamics of group interactions. This paper presents the experiences of two students, studying through Open Universities Australia, on their personal experiences with online group work. These students were consulted about their experiences after completion of the relevant unit, in an attempt by their lecturers to gain insight into the challenges faced by students:

Considering the popularity of collaborative learning methods in current online programs, educators must understand how participants experience their online learning so that more effective courses and activities can be developed (Heejung et al. 2008, p. 67)

\section{Implementing group work for off campus students}

Much of the off campus teaching at Swinburne University of Technology is conducted through Open Universities Australia (OUA). These units are offered as fully online units, and adhere to the open university philosophy of open access to all (i.e. there are no prerequisites for entry into OUA, so students may not have completed secondary education; for more information, see http://www.open.edu.au/). OUA students have the opportunity to graduate with a degree from one of the contributing universities, so to meet accreditation requirements, each unit offered through OUA must be identical to an equivalent unit offered to students enrolled through the relevant university. This means that we have a responsibility to ensure that all students, regardless of whether they are studying on or off campus, have access to the same opportunities to develop both discipline-specific skills and generic skills.

This requirement reinforces our existing desire to include opportunities for student collaboration and teamwork in all online courses, based on evidence that collaborative learning has been associated with higher achievement, increased motivation, and greater interaction between students (as discussed by Neumann \& Hood, 2009). We subscribe to Vygotsky's (1978) social learning theory that emphasises the importance 
of peer-based interaction and knowledge sharing in individuals' construction of knowledge and understanding. This is particularly emphasised in the learning materials for the unit described in this paper, where the need for students to not only share knowledge but also build an intersubjective group relationship to enhance their possibility for success is stressed (Dirkx \& Smith 2004).

A group project for off campus students was trialed in an introductory study skills unit in 2008. The project was intended to not only help students to develop their theoretical understanding of a chosen topic, but also to provide the opportunity to develop their teamwork skills through collaboration. To encourage this, a proportion of the total marks for the project were awarded for evidence of an individual student's contribution to the teamwork processes (discussed in more detail in the next section).

Wikis were implemented as the online collaboration technology. A key feature of interest for our purposes was the ability of wikis to display a history of the versions created for each page and allow easy comparisons between different versions, so teaching staff can identify who has contributed and to what extent.

The group project using wikis has now been run successfully for six consecutive study periods. The trial was successful in that students were given the opportunity and technical means to collaborate, and staff were able to assess individual students' participation. The actual level of collaboration was less than hoped for, especially in the early iterations of the unit; however by providing more focus on this in subsequent iterations, this has increased markedly. The outcomes of the initial trial and subsequent implementation have been reported previously (McIntosh \& Weaver, 2008; Weaver \& McIntosh, 2009), including staff and student feedback. While the teaching team are confident that, for the overall student cohort, collaborating online using a wiki is meeting the needs of most students, this is varied across the cohort, and especially so given the diverse group of students enrolling through OUA. An individual student's experience is largely determined by the other members of their group - those who are lucky enough to be part of a motivated group with high academic standards will gain an enormous amount from such an experience, yet their peers who find themselves in a disengaged group will end up either disengaged themselves, or spending enormous amounts of energy trying to motivate their colleagues.

During our trials with the wiki project, several of our students contacted us privately to share their experiences. This paper reports on two of these stories, as well as the reflections of the Unit Convenor, and compares the experiences described by these students with the teaching staff members' perceptions. The two students featured here (and also included as co-authors of this paper) were selected not just for their articulate writing, but because their group experiences were quite different. These students are obviously highly motivated, so cannot be claimed to be representative of their wider student cohort. Nevertheless, their reports give educators greater insight into student experiences in off campus group work.

\section{The group project}

SSK 13 Learning and Communication Behaviour is a study skills unit offered to students who are beginning a degree course through OUA, with enrolments each study period of 50-100 students. Students initially completed individual research on a given topic in 
the form of an essay. The topic provided for several cohorts in 2008 was "The history of globalisation", and was chosen as it allowed students sufficient scope to explore areas of individual interest under this broad area. This topic was then used as a basis for developing an understanding of the modern manifestation of globalisation, explored further in the group project. A number of areas of research were suggested to investigate the expression of globalisation in the world (e.g. celebrity, sport, popular movements such as Live Aid, etc).

The project extended over six weeks, with other course work continuing concurrently. All students were encouraged to participate in weekly online chat sessions with their tutors and reminders about the group project were frequently provided at these sessions. All wiki groups were 'private' to start with (where only the group members and teaching staff had any access) but were opened up as 'protected' sites after the due date for the assignment passed. This meant that other groups were then given read only access to each other's finished product.

The group project was worth $40 \%$ of the semester grades for students, so it was a significant component of the unit assessment. All active members of a group received the same mark for the project. Active members were defined as any student who had contributed, to any extent, to the wiki (i.e. had accessed the wiki and contributed at least one edit). This constitutes a mark for the 'product' from the group. An additional $15 \%$ was allocated to students individually (making the project worth a total of 55\% of the semester marks), on the basis of their demonstrated team work, thus constituting a mark for the 'process' of group work. A simple rubric for this component was developed, and provided to students at the start of the project (see Weaver \& McIntosh, 2009). Evidence of effective team work included demonstrated leadership, encouragement of peers, editing others' work, setting high standards etc, and was assessed by consulting the history of edits to the wiki, and the content of comments posted within the wiki. Students were notified about this before the project began, and advised that if they conducted online meetings outside the wiki environment (e.g., using Skype, chat rooms or private emails), they should post the minutes of such meetings into the wiki comments area. Of necessity, assessors were flexible with the use of the marking rubric, to allow for students who were unable to exhibit team work skills due to unresponsive colleagues in their groups. In these cases, attempts at communication and standard setting were deemed to be sufficient.

\section{Group selection}

For the first iteration (i.e. the program pilot), the teaching team placed students into groups of around six, based on the time zone where students lived, believing that this would make it easier for students to organise live chat or Skype sessions without worrying about time differences. However, there is a large dropout rate with OUA students (probably more accurately termed a 'non-commencement' rate rather than a dropout rate), and since these students don't officially discontinue their enrolment, we must assume that they may still become active in the unit. This meant that most groups included inactive members, and in some groups meant only two students were working on the wiki. In the next iterations, students who actively participated in the weekly online chat sessions were encouraged to form their own groups, with the remaining students allocated to groups by the teaching staff. This was more successful for those students who were participating in the tutorials regularly; however students who were active in the unit but could not participate in the online chat sessions (for 
example, work commitments at that time) still found themselves in groups with inactive or missing members. The most recent method of group selection still incorporates the self-selection aspect described above, with the remaining students allocated on the basis of whether they submitted the individual assignment prior to the group project commencing. This has been the most successful method so far, and allows us to aggregate those students who are unlikely to commence the unit together.

\section{Student support}

Various student support resources were provided for this project. An introductory video demonstration on using wikis was made available in the unit's Blackboard site. This was supported by a step by step manual covering the key technical steps of wikis, available online as a PDF document. Additional support was provided via scheduled online chat sessions with key staff - one at the start of the project (mostly covering access issues and getting started) with a follow up session about half way through the project, when students were beginning to explore the capabilities of the technology. Participation in these sessions was optional. Ongoing and personalised support was also provided on demand, both via the unit's Blackboard site, and via email and phone contact with the project managers (the Unit Convener and the Academic Developer).

\section{Feedback from Unit Convenor}

The Unit Convenor provided the following account of his experiences with incorporating the wiki into his teaching, and his observations on the level of collaboration within student groups.

Due to earlier, less successful experiences, I began this project with some concerns about the team-forming process. Some teams were formed by students, on the basis of involvement in weekly tutorial chat sessions. This meant that these students had an advantage in that they had already established relationships with each other prior to being put into a team. These teams generally performed strongly (not surprising, since these were often the more motivated students); however, these students were in the minority in the course. Those who did not participate in these tutorials were much more reliant on teaching staff to form them into groups. The main problem with this process was the inevitable delay in starting their project. However, once all organisational delays were dealt with, the projects generally progressed well and with surprising success.

Informal evaluation was undertaken during the early wiki trials, by the teaching team posting questions about progress (both technical and collaborative) on discussion boards. Other feedback was received from students during the weekly online chat sessions (from those who participated), and more formal feedback was received in institutionally-administered surveys at the end of each study period (although without specific reference to the group project). I was pleased with the student feedback on the group process, expressing their initial serious doubts that a satisfying and successful team learning process could be achieved online, but that to their surprise, using the wiki format, they achieved that satisfying and successful experience that they doubted was possible.

During the group project, I was privy to some reports from those students and groups who regularly participated in the tutorial chat process. These groups appeared to be cohesive and well organised. This was expressed through the allocation of specific tasks to individuals within the team, evidence of regular team meetings to develop their wikis and regular contact with teaching staff to clarify questions about construction of the wikis. 
However, for those who were not engaged in the tutorial chat sessions, I assumed that the teams were collaborating along similar lines. This was based on my assumption that team members were reading the announcements which were posted regularly on the unit's website, giving detailed advice on how to work collaboratively, and supported by learning materials that also explained how the collaborative process should work and the stages that teams should expect to go through. These expectations were notionally supported by the relative lack of contact from those teams that did not engage in the weekly chat sessions. All students in the unit were encouraged to keep in as regular contact with their tutor, or myself as convener, as they felt they needed.

The process we wished the students to engage in was a genuinely collaborative process, where the particular assignment task was broken down into individual components and each component was allocated a wiki page and was then to be written in academic prose with all team members contributing to each component. However most teams delegated sub-topics to individuals to work on, only coming together at the end to work on the Introduction and Conclusion sections of the wiki. In this aspect, our students echoed the strategy imposed by staff in a similar wiki project (Carr et al, 2008). The majority of students appeared surprised at how effectively they could work collaboratively, albeit an amended form of collaboration.

Although students generally divided up the work strategically, rather than working collaboratively, they needed to use their collaborative skills to coordinate the construction of the wiki from a number of individual components. This appears to be where the students identified the main collaborative element. The more engaged students identified a strong sense of collective identity based on their group and the wiki they produced. Those who were less engaged apparently felt less sense of a group identity and did not communicate to us the same sense of pride in the success of their achievement. Nonetheless, formal student feedback on completion of the unit reflected broad approval of the wiki process.

\section{Student experiences}

In this section, two off campus students describe their experiences working in online groups. As mentioned above, these students' stories were selected after they privately contacted the teaching team to discuss the individual processes they went through, which amounted to very different experiences.

\section{Experience of Student A}

At the start of this unit, I felt disorganised and overwhelmed by the amount of information which was involved. I think possibly because this was the first time I had done any study since high school. Even though I was feeling scared I was also excited to be doing something new, expanding my horizons and learning. Now, at the end of this past 12 weeks I am on top of the disorganisation, but still a little overwhelmed by what's out there in the way of information.

The first chat session seemed tense and we talked about the essay and about forming the groups for the wiki. I wasn't comfortable because I didn't know anyone. The whole atmosphere was formal and matter of fact. As time went on the regular 'chatters' kept coming and the mood lightened and the sessions proved to be an important part of the course. We were getting to know each other and becoming friends. Even our tutor became playful at times, and that really relaxed the sessions, but she also knew when to bring things back under control - something I had to get into the habit of doing. 
Our tutor suggested that we form our group based on who attended the tutorial chat sessions. Fortunately, we did not have to decide during that first chat session but by the time it came to forming the groups, we were all happy to go along with it. We had established a bond with each other and were comfortable in our surroundings.

When the group work started for real, I mainly focused on getting the information together for my page. I volunteered to be the leader of the group, I thought it might give me a bit of confidence, and it did. I also played around with the wiki software to see what could be done with it and developed our home page, which was fun! The other members of the group liked it as well. The group chats were the best thing about doing the wiki. We got together twice a week and most of the time everyone turned up. I really looked forward to these chats - it was like a group of friends getting together and having a cup of coffee, talking about the work and having a bit of fun, all at the same time. For the most part, we did our individual pages but we also made comments and suggestions on each others', and when someone in the group needed a bit of help we were always willing to assist. In our last two chat sessions, we got down to business and shaped the wiki into something that I am really proud of.

The contributions from all members of the group were invaluable. Each member was asking questions and suggesting alterations appropriate to each other's page.

Everyone was willing to help others if they were having problems with either the technical or academic aspects of the wiki, such as formatting, referencing and even down to the font we were using. A couple of us got nicknames, for example The Referencing Queen and the Font Nazi. Neither of these terms were used in a derogatory sense, they were a part of our fun. I think we all wanted to do well and seeing this, the group helped each other equally. In this way we could achieve something that was of a very good quality overall. We all appeared to be of an equal academic level. For most of us this course was the first, or one of the first, we were undertaking at university. I felt I was on an equal footing with everyone else. Although we all had our own style of writing all the pages appeared to meld together when the final product was submitted.

I did have one unpleasant experience. I commented on one page and thought the comment was ok, but when I received an email from the owner of the work saying she was getting annoyed and she was happy not to take any further part, I was disheartened. I didn't want her to lose marks for not participating. My thoughts turned to the Dirkx and Smith (2004) reading. So many of the people in the case studies in the chapter seemed to have a distressing time. I felt bad and returned the email with an apology. I also added to my comments on her page. I didn't mean to offend and we got on really well afterwards. In a way the experience has already helped me amend my ways. I have used what I learned in another situation by being more tactful with my comments instead of being as subtle as a brick in the face. I looked forward to having my work scrutinised and edited by my peers and I appreciated the comments that were left for me. They were constructive and helped me to think in other ways about the subject I was approaching with my page.

The opportunity to work with others, in an online project like the wiki, was a new experience for me and I enjoyed the challenge presented by this course. We all liked the final output and were pleased that it came together so well, although some of the technical restraints of the software made it frustrating at times. It looked good and had a great deal of information, despite the word limit imposed on us. I felt a sense of accomplishment when the final results came through.

By the end of the course we were all comfortable with each other. During our chat sessions we joked around but we also got down to the business of putting the wiki together. We seemed to be a cohesive group and I think that was because we participated in regular chats and got to know each other, even though it was in a 
limited capacity. I couldn't wait to get into the chat room on chat nights. At the last chat session we all said we would try and keep in contact and I have managed to maintain communication with one of the other students and our tutor, as well as other teachers in the unit. I knew the end was getting close but that still didn't stop me feeling a sense of loss, I really missed going to the chat room for a few weeks after the course finished!

I would recommend that everyone does join the chat sessions. I know that not everyone has the time to join in, but it is an important part of working together in a group. Overall the course was a positive experience for me, except for the one little glitch.

\section{Experience of Student B}

My group for the wiki project consisted of five members, and after logging in and being given the assessment, it was clear to three of us that one member wouldn't be participating at all, and that another member was content to act on his own accord. The group had been selected by the lecturers, and for the three of us, this was the first time we had been asked to complete a group assessment. We found many things in common, which helped form our working relationship; we were all in the same age bracket, with many other constraints on our time.

I felt that if we arranged regular online meetings, it would give the group some structure, and we would feel as though we were working together, even though we were all kilometres apart. I decided to initiate weekly meetings through MSN Messenger, for one hour, to discuss which topics we would like to take, and update each other on our progress. Eventually we formed a great working relationship. Another team member was the first to post an introduction for us and the writing kept coming from there. That colleague was a wonderful source of information and was able to edit my writing without issues; another team member was less interested in editing others' work, preferring to concentrate on her own part instead.

We found that our fourth team member did not participate in discussions at all, and rather than post his contribution to the Wiki and allow his colleagues to read and edit if necessary as the rest of us had done, he sent his essay to Smart Thinking (a resource available to OUA students, where online tutors give feedback on student work), and posted it only a few days before the entire group task was due. This led the three main contributors to feel completely let down. Here we were, collaborating with each other, accepting editing and constructive criticisms, and this silent member of the group was totally ignoring us. I made the other member aware of our feelings through a very carefully worded email, inviting them to participate in more of the 'team work' so as to feel included, and received no response. Eventually the two other students and I decided to cut our losses and focus on how we could further improve the wiki.

I assumed the role of 'leader' in the group task, as I believe this is my nature. I prefer to lead and organise than follow; however one colleague was also proactive, drafting introductions and conclusions, leaving the 'decorating' of the wiki to myself.

One of the challenges our group faced was the fact that our fourth member did not appreciate his work being edited, and did not respond when we commented on the suggestions; he also did not participate in the decision to add images to the wiki, and ended up adding many attachments that slowed the overall performance of the site. Eventually the three active collaborators were able to agree that we had done the best we could with the topic and group we had been given, and that there was nothing more we could do to improve the wiki with unresponsive members. We submitted the wiki on time and were quite pleased with our marks. I felt that the fact that our group had a leader aided the group work, as each person was delegated a responsibility, and 
was able to take ownership of not only their page, but also their responsibility. I believe this enabled us to work together effectively and become friends in the process.

The chat room was a challenge for me at first but is simple now. I thought dividing the members into tutorial groups was a great idea, as it saved us all time having to meet and greet everyone else; similarly with the group tutor, having our own tutor was wonderful, I didn't need to repeat my questions as she always remembered where we had left off.

Overall, this unit has helped me gain experience in a wide variety of university skills, from referencing and essay writing to technical aspects such as Blackboard and chat rooms. I have also gained valuable experience in time management. I now understand how knowledge is different to skills, how online study is different to on campus study, how different students learn effectively, and more importantly how I prefer to learn as a student. I have realised that not all learning comes from a textbook or handbook and how much commitment is required to study at university. I understand what role I prefer to play within a group or team; and the most important thing I have realised is that not all the information available on the Internet is reliable!

I feel a great sense of satisfaction after completing the majority of this unit. After a rocky start, and a terrible first attempt at my globalisation essay, I have put a lot more effort into the second half of the study period, and feel quite confident about our wiki project and my later work. While I do not expect to be the top of the unit, I feel as though I have put in enough effort to ensure a pass, something of which I am proud. I know that when I start the rest of the units I will be taking to obtain my degree, I will be starting them with a better understanding of what is required of me, and with a more confident approach than I had at the beginning of SSK13.

\section{Discussion}

Stories from two students cannot be claimed to constitute a representative sample of the whole class, especially since these are self selected as more motivated and more articulate students. However, reading through the reflections provided by the two students included here does provide examples of the student voice, and allows teaching staff to gain more insight into the experiences of our students.

For example, we now realise how naïve we were, in relying on the feedback we were receiving to form our judgment on what was actually happening within the student groups. Obviously, the more motivated and engaged students are more likely to be active participants in regular chat sessions, more frequent contributors to discussion boards, and more likely to separately contact teaching staff, and these are the experiences we are more likely to be familiar with. In this context, Student A's experience tallies closely with our beliefs of how the groups were functioning. Where groups included students with diverse motivations, we had expected staff to be consulted more on how students could deal with their recalcitrant colleagues. While we were consulted on occasions, this was primarily for advice on how to deal with students who had failed to make any contact with team colleagues, or failed to contribute at all towards the project. The personal experience from student B (where a team member contributed to the project but refused all attempts at collaboration) indicates non-participation may actually be less disruptive to the team processes than a student who actively rebuts all attempts at cooperation, yet still expects to be recognised as a team contributor. 
So what can teaching staff do, to better support our students in this? Because Student A's group involved all members working together, the process of collaborating was easy. The regular chat sessions and communication within the group provided a good basis for a working relationship, and they found that through regular communication and discussion, their interaction was more cohesive and productive. Student A suggests that members of groups implement a regular communication plan, so they all have access to the same information. This process may tempt non-active members to become more actively involved in the collaboration process. A single group member can be elected to be tasked with emailing a copy of the chat session transcript to all members of the group. He also suggests establishing the groups a little earlier in the course, and encourage group members to begin communication before the collaboration work starts in earnest. This may put the members of the groups at ease with each other and make it easier for them to begin to bond.

Student B suggests that students need to take the responsibility for their team contributions. She doesn't believe that teaching staff could or should do any more to prompt the students, although training in dealing with group issues may be of benefit:

The support we received was fantastic, and whenever we had a question it was answered almost immediately. I feel that it was the support from the lecturers that helped and motivated me to achieve a distinction for the unit. Looking directly at the few issues I had in my group, perhaps a brief tutorial regarding dealing with challenges in group work, or responding to confronting words may help?

However, we may ultimately have to acknowledge that some students will always resist inclusion as part of a team. As Elgort et al (2008) found, "the use of wikis was not enough to counteract some students' preference for working alone rather than as part of a team" (p. 208).

Both students reported benefiting from colleagues editing or providing critical comment on their own contributions, and both claim to be comfortable with this process. Neither student reported feeling any hesitancy in providing their own critiques on colleagues' work (although Student A did report a colleague's distressing response to a critical comment, and learnt how better to frame critiques in future). We had expected more reluctance to criticise other's work, as reported by Miers et al (2007):

Students reported benefiting from the peer review process but were uncomfortable with critiquing each other's work. (Miers et al 2007, p529).

Staff felt strongly prior to and throughout the group project that where groups engaged in truly collaborative work, the end product would be of much higher quality than what individuals could have achieved working alone. The experiences of these two students support this belief - even in the group with one non-participant and one non-collaborator, Student B believes the remaining students produced a wiki they were all proud of. This is supported by the literature in the field, that students who work in teams '.. benefited from the greater knowledge base and from collective information processing' (Krause et al. 2009, p167), and '... are much more likely to reach superior decisions than individual students left to their own knowledge'(Wilson, 2005, p288).

Unfortunately, few of our student groups were observed to exhibit collaboration. Most groups delegated tasks to individuals within the group, and so behaved cooperatively 
rather than collaboratively. Our observations support the findings of Judd, Kennedy and Cropper (2009), who also found that students largely worked as individuals within the wiki. Their experiences differed slightly from ours, in that they found that the majority of contributions were made late in the project, so did not allow time for collaboration to occur. Our experience was that most of the active students worked at a fairly even pace throughout the project, but most tended to work on their own section of the project, and only consulted their colleagues' contributions during the consolidation phase. Judd, Kennedy and Cropper (2009) go on to remind us that

[t]his acts as a timely reminder that designing learning activities that are collaborative in nature, or simply using 'collaborative' technologies, does not guarantee students will work together in cohesive way (p10).

Selection of group members may be the key area where student experiences can be improved. We have tried several different methods of group selection, and currently allow students who are more active in chat sessions to form their own groups, with staff then allocating remaining students into groups. This method was intended to allow more engaged students to work together, without being held back by less active participants. However, it appears that many highly motivated students do not participate in the chat sessions (for a variety of reasons, which may include work or family responsibilities), and there is no compulsory expectation that students must participate in these sessions.

It appears that we teach two cohorts of students: those who engage with the course as fully as possible; and those who prefer to work at their own pace with minimal engagement, only involving the occasional email to a tutor for clarification. However the assumption that these are the self-motivated students who are content with a 'hands off' approach is not a reasonable assumption to make, but one the teaching staff tend to err to. These students may be slow to engage with their wiki group and leave work on the wiki until the last moment. It has become increasingly apparent that despite the fact that these students seem, positively or negatively, reticent to engage in other online activities, they need preemptory intervention in order to maximise their engagement with the wiki group and as a result, with the collaborative process. One of the important elements discussed in the literature about successful implementation of a collaborative project is to establish a social connection with other group members, and the establishment of these relationships needs to happen early in the process and cannot be successfully done with a pressing deadline (Dirx \& Smith, 2004; Caspersz, Skene \& $\mathrm{Wu}, 2006)$. Early intervention strategies need to be developed by staff to facilitate the engagement of these reluctant students, both for the benefit of these students and of their fellow group members.

Accordingly, we are currently trialing different methods of wiki group selection. In one method, students compulsorily nominate a standard at which they would like to work and are then matched with fellow students on that basis. Secondly, students are matched up on the basis of their first individual assignment mark. Both these strategies have had limited success. Our most recent method involves administration of a questionnaire to the students, asking for an element of personal information they are willing to share with peers, together with some academic background and achievement level expectations. This last strategy is still in development. 


\section{Conclusions}

An online group project for off-campus students, using wikis as the collaborative platform, has been running for several consecutive study periods (Weaver \& McIntosh, 2009), and has successfully provided an opportunity for students to build social bonds with peers online. Personal reflections from two students, while not a representative sample of the whole class, have nevertheless provided insights into the team strategies and challenges occurring within the student groups, and allowed comparisons between truly collaborative groups, and those which included students of varied motivations.

Considering these students' experiences has allowed the teaching staff to reflect on how we might better support our students during their group project. Already more emphasis on the need (and benefits to students) of collaboration has been included in the project descriptions, and highlighted by tutors. Example wikis from previous study periods, demonstrating the relatively high standard of this form of collaborative activity, are demonstrated to each new cohort of students, together with selective comments from student feedback attesting to the value of this form of assessment. This student endorsement is particularly powerful in light of some students' skepticism about being able to work collaboratively from remote locations. Also, as the use of wikis in our teaching has progressed, tutors are able to draw on the experience that students have in the use of social networking sites to highlight the "everyday" experience of working with multiple people in the one online environment.

Our group selection methods are still in development, with several different strategies being trialed with different student cohorts.

We also hope to take the assessment of teamwork skills further, and provide feedback to individual students on their own progress in this area. While the wiki project is a summative assessment task, and the timing of such feedback cannot help students improve their performance in this unit, team work is a generic skill, and constructive feedback can help students in future group projects, and in their field of employment.

\section{Acknowledgments}

The authors wish to thank two anonymous reviewers for providing feedback on an earlier version of this paper, and to the Editor of AJET for further feedback and clarification.

\section{References}

Augar, N., Raitman, R. \& Zhou, W. (2004). Teaching and learning online with wikis. In Beyond the comfort zone: Proceedings ASCILITE Perth 2004.

http: / / www.ascilite.org.au/conferences/perth04/procs/augar.html

Brack C., Stauder, A., Doery, J. \& Van Damme, M-P. (2008). Collaborative learning online: Integrating media in case-based learning for clinical biochemistry. In C. Montgomerie \& J. Seale (Eds.), Proceedings of World Conference on Educational Multimedia, Hypermedia and Telecommunications 2007 (pp. 187-192). Chesapeake, VA: AACE.

Carr, T., Morrison, A., Cox, G. \& Deacon, A. (2007). Weathering wikis: Net-based learning meets political science in a South African university. Computers $\mathcal{E}$ Composition, 24(3), 266-284. 
Caspersz, D., Skene, J. \& Wu, M. (2006). Managing student teams. Higher Education Research and Development Society of Australasia, Milperra, NSW.

Dewiyanti, S., Brand-Gruwel, S. \& Jochems, W. (2005). Applying reflection and moderation in an asynchronous computer-supported collaborative learning environment in campus-based higher education. British Journal of Educational Technology, 36(4), 673-676.

Dirkx, J. M. \& Smith, R. O. (2004). Thinking out of a bowl of spaghetti: Learning to learn in online collaborative groups. In T. S. Roberts (Ed), Online collaborative learning: Theory and practice. Hershey: Information Science Publishing.

Elgort, I, Smith, A. \& Toland, J. (2008). Is wiki an effective platform for group course work? Australasian Journal of Educational Technology, 24(2), 195-210. http: / / www.ascilite.org.au/ajet/ajet24/elgort.html

Heejung, A., Sangkyung, K. \& Bosung, K. (2008). Teacher perspectives on online collaborative learning: Factors perceived as facilitating and impeding successful online group work. Contemporary Issues in Technology E Teacher Education, 8(1), 65-83. http: / / www.editlib.org/d/24290/article_24290.pdf

James, R., McInnis, C. \& Devlin, M. (2002). Assessing group work. Centre for the Study of Higher Education: The University of Melbourne. [viewed 22 Oct 2009, verified 17 Oct 2010] http:/ / www.cshe.unimelb.edu.au/assessinglearning/03/group.html

Judd, T., Kennedy, G. \& Cropper, S. (2010). Using wikis for collaborative learning: Assessing collaboration through contribution. Australasian Journal of Educational Technology, 26(3), 341354. http:/ / www.ascilite.org.au/ajet/ajet26/judd.html

Krause, U.-M., Stark, R. \& Mandl, H. (2009). The effects of cooperative learning and feedback on e-learning in statistics. Learning $\mathcal{E}$ Instruction, 19(2), 158-170.

McIntosh, P. C. \& Weaver, D. (2008). Fostering collaboration amongst off-campus students. In Hello! Where are you in the landscape of educational technology? Proceedings ascilite Melbourne 2008. http:/ / www.ascilite.org.au/conferences/melbourne08/procs/mcintosh.pdf

Miers, M. E., Clarke, B. A., Pollard, K. C., Rickaby, C. E., Thomas, J. \& Turtle, A. (2007). Online interprofessional learning: The student experience. Journal of Interprofessional Care, 21(5), 529542.

Minocha, S. \& Thomas, P. G. (2007). Collaborative learning in a wiki environment: Experiences from a software engineering course. New Review of Hypermedia \& Multimedia, 13(2), 187-209.

Neumann, D. L. \& Hood, M. (2009). The effects of using a wiki on student engagement and learning of report writing skills in a university statistics course. Australasian Journal of Educational Technology, 25(3), 382-398.

http: / / www.ascilite.org.au/ajet/ajet25/neumann.html

Raman, M., Ryan, T. \& Olfman, L. (2005). Designing knowledge management systems for teaching and learning with wiki technology. Journal of Information Systems Education, 16(3), 311-320.

Vygotsky, L. S. (1978). Mind in society. Harvard University Press, Cambridge, MA.

Weaver D. \& McIntosh, P. C (2009). Providing feedback on collaboration and teamwork amongst off-campus students. In C. Fulford \& G. Siemens (Eds.), EdMedia 2009 - World Conference on Educational Multimedia, Hypermedia and Telecommunications, Hawaii, USA June 2009 pp 20702079. 
Wilson, P. (2005), Mutual gain from team learning: A guided design classroom exercise. Review of Agricultural Economics, 27(2), 288-296.

Zorko, V. (2009). Factors affecting the way students collaborate in a wiki for English language learning. Australasian Journal of Educational Technology, 25(5), 645-655. http: / / www.ascilite.org.au/ajet/ajet25/zorko.html

Corresponding author: Debbi Weaver is a Senior Lecturer and Academic Development Advisor at Lilydale Campus, Swinburne University of Technology, Australia.

Contact: Debbi Weaver, Academic Development Adviser, Swinburne Professional Learning, Mail L03, Locked Bag 218, Lilydale Vic 3140.

Email: dweaver@swin.edu.au

Shane Viper is a student, undertaking studies at Swinburne University of Technology, via Open Universities Australia.

Email: shane@realtasmania.com

Jennifer Latter is a student, undertaking studies at Swinburne University of Technology, via Open Universities Australia.

Email: jenlatter@yahoo.com.au

Craig McIntosh is a Lecturer at Swinburne University of Technology.

Email: cmcintosh@swin.edu.au 